\title{
MANIFESTAÇÕES BUCAIS DA SÍNDROME DE APERT: RELATO DE CASO CLÍNICO
}

\section{EXPRESSIONS OF ORAL APERT SYNDROME: CLINICAL CASE REPORT}

\author{
Letícia Dias Gomes* \\ Alexandre Marques Paes da Silva* \\ Patricia Nivoloni Tannure"
}

\begin{abstract}
RESUMO
A Síndrome de Apert, também chamada de acrocefalossindactilia tipo 1, é caracterizada pelo encerramento prematuro das suturas cranianas (craniossinostose), sindactilia simétrica das mãos e dos pés e anomalias faciais. Outras anormalidades observadas são atraso mental, anquilose articular e anomalias da coluna vertebral. Destacam-se, ainda, a hipoplasia da face média com Classe III, lábios hipotônicos, úvula bífida, erupção ectópica, má oclusão e pseudofenda palatina. A cavidade bucal desses pacientes apresenta normalmente uma redução no tamanho da maxila, em particular na direção anteroposterior. Essa redução pode resultar em apinhamento dentário e uma mordida aberta anterior. A mandíbula está dentro do tamanho e da forma normal, e simula um pseudoprognatismo. Anomalias dentárias, tais como dentes inclusos, erupção retardada, agenesia dentária, hipoplasia do esmalte, dentes ectópicos ou supranumerários são comumente observadas. Diante da necessidade de um tratamento multidisciplinar e da relevância do cirurgião-dentista no acompanhamento desses pacientes, o objetivo deste relato é descrever as manifestações bucais da síndrome, enfatizando as características mais frequentes no período de transição da dentição decídua para a dentição permanente.
\end{abstract}

Descritores: Síndrome de Apert, Maloclusão, Cárie dentária, Anormalidades dentárias

\section{ABSTRACT}

Apert syndrome, also called acrocephalosyndactyly type 1, is characterized by the premature closure of the cranial sutures (craniosynostosis), symmetric syndactyly of the hands and feet and facial anomalies of the midline. People with Aper syndrome have craniofacial abnormalities as exophthalmos, ocular hypertelorism, broad and short nose with a bulbous tip. The patients have hypoplasia midface with Class III, hypotonic lips, cleft uvula, ectopic eruption, malocclusion and pseudo cleft palate. The oral cavity usually these patients showed a reduction in the size of the jaw, in particular in the rearward direction. This reduction may result in tooth crowding and in an anterior open bite. The jaw size is within the normal way and simulates a pseudoprognathism. Dental anomalies, such as impacted teeth, delayed eruption, tooth agenesis, enamel hypoplasia, ectopic or supernumerary teeth are commonly observed. Given the need for a multidisciplinary approach and the relevance of the dentist in monitoring these patients, the objective of this report is to describe the oral manifestations of the syndrome emphasizing the most common features in the transition period of the deciduous dentition to the permanent dentition.

Descriptors: Acrocephalosyndactylia, Malocclusion, Dental caries, Tooth abnormalities.

* Graduada em Odontologia - Universidade Veiga de Almeida (UVA)

** Mestrando em Odontologia (Reabilitação Oral) - Universidade Veiga de Almeida (UVA)

*** Doutora em Odontologia (Odontopediatria), Professora da Disciplina de Odontopediatria - Universidade Veiga de Almeida (UVA) 
GOMES LD

SILVA AMP

TANNURE PN

MANIFESTAÇÕES

BUCAIS DA

SINNDROME DE

APERT: RELATO DE

CASO CLÍNICO

278

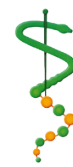

REV, ODONTOL

UNIV, CID, SÃO

PAULO

$2016 ; 28(3): 277$

84, SET-DEZ

\section{N T RO DUÇÃO}

A síndrome de Apert é uma desordem genética ocorrida ao nascimento e que causa um desenvolvimento anormal da caixa craniana. É considerada dominante autossômica, pode estar relacionada a herança paterna e a idade avançada e está associada a mutações no receptor do fator de crescimento de fibroblastos FGFR2. O risco de recorrência para os pais não afetados de uma criança com essa síndrome é desprezível, ao passo que para os indivíduos afetados é de 50\%. Quanto aos aspectos genéticos, é causada por substituições específicas envolvendo os aminoácidos adjacentes Ser 252Trp e Pro 253Arg na ligação entre a segunda e a terceira alças de imunoglobulina de domínio do FGFR2 ${ }^{1}$.

A síndrome tem como característica importante a craniossinostose grave que se dá pelo fechamento prematuro de uma ou mais suturas cranianas, além de defeitos nas mãos e pés. Foi relatada pela primeira vez em 1894, e o nome foi definido somente após muitos casos terem sido descritos pelo pediatra francês Eugene Apert em 1906. A síndrome representa aproximadamente 5\% de todas as síndromes com craniossinostose e tem uma prevalência rara, em torno de 1 em 65.000 a 160.000 nascimentos. A síndrome ocorre em cerca de um para cada cem mil a cento e sessenta mil nascimentos. Embora seja hereditária, ligada a um gene autossômico dominante, muitos casos representam novas mutações esporádicas, muitas vezes associadas com a idade avançada dos pais $^{2}$. De um modo geral, o paciente apresenta anormalidades craniofaciais, como exoftalmia, hipertelorismo ocular, nariz largo e curto com uma ponta bulbosa. Além dessas também são encontradas sindactilia simétrica das mãos do $2^{\circ}, 3^{\circ} \mathrm{e}$ $4^{\circ}$ dígito e dos pés e alterações sistêmicas. Dentre as alterações craniofaciais a hipoplasia do terço médio de face com Classe III é uma das mais evidentes. Existem também manifestações como lábios hipotônicos, úvula bífida, erupção ectópica, má oclusão e pseudofenda palatina que acontece devido à hiperplasia do arco da maxila. Outras anomalidades observadas são atraso mental, anquilose articular e anomalias da coluna vertebral. Frequentemente, observam-se maloclusão, facetas de desgastes anormais e erupção atrasa$\mathrm{da}^{3}$.

O objetivo deste relato de caso foi descrever as manifestações bucais de um paciente portador de Síndrome de Apert, desde a sua infância até sua adolescência. Busca-se, com o presente trabalho, enfatizar a importância do conhecimento acerca das manifestações bucais e sinais patognomônicos da doença que ocorrem durante a transição da dentição decídua e permanente, além de alterações craniofaciais pertinentes ao manejo do cirurgião-dentista.

\section{RELATO DE CASO CLÍNICO}

Paciente B.S.D., do gênero masculino, portador da Síndrome de Apert, apresentou-se ao consultório, com 10 anos e 11 meses de idade, para iniciar o tratamento odontológico. Na primeira consulta, ao exame clínico extraoral, pôde-se observar a presença de osso occipital achatado, osso frontal pronunciado anteriormente,

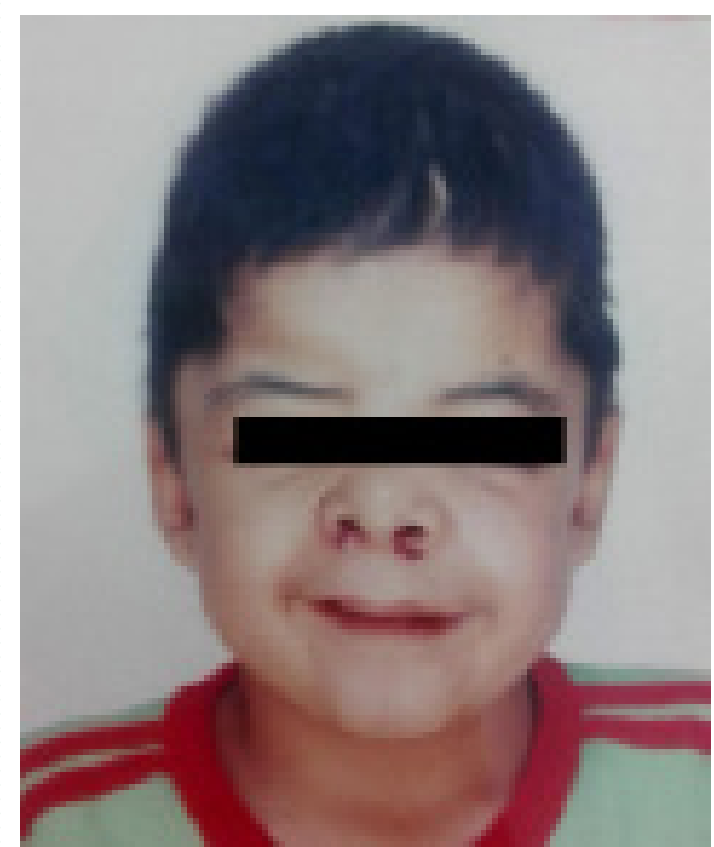

Figura 1: Foto da face do paciente mostrando turricefalia, fissuras palpebrais laterais para baixo com aspecto antimongoloide, nariz largo e curto com uma ponta bulbosa, lábios hipotônicos e desvio de linha média. 


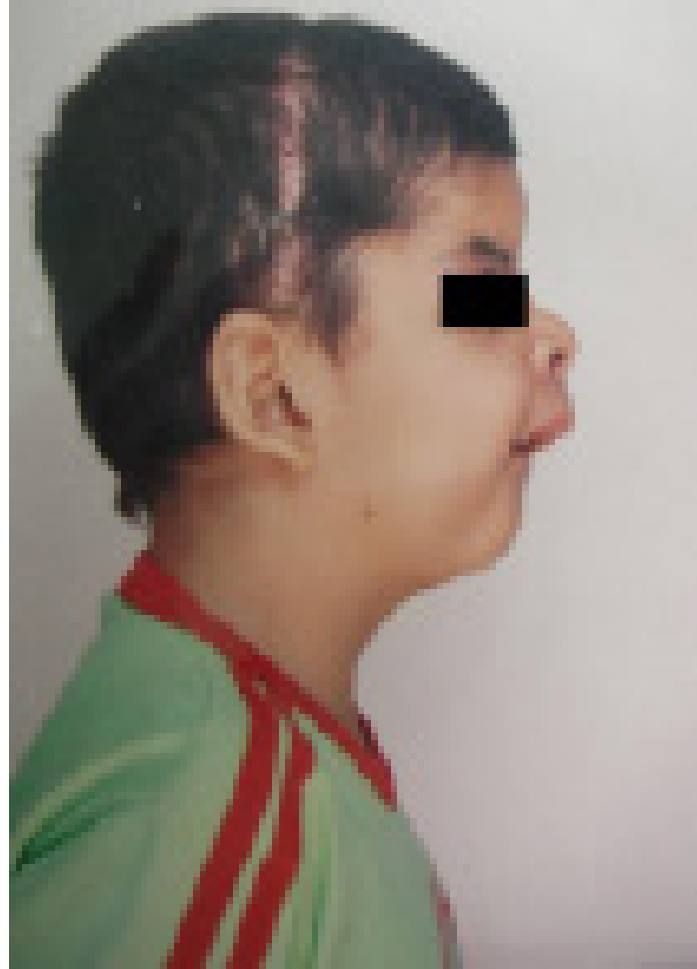

Figura 2: Foto de perfil mostrando o terço médio da face avançado semelhante à má oclusão do tipo Classe II.

turricefalia, fissuras palpebrais laterais para baixo com aspecto antimongoloide, nariz largo e curto com uma ponta bulbosa, lábios hipotônicos e desvio de linha média (similar ao padrão clínico extraoral dessa síndrome). O terço médio da face apresentava-se avançado, semelhante à má oclusão do tipo Classe II. Diferente do que é observado na síndrome, essa alteração pode ser justificada por cirurgias e terapias realizadas previamente (Figura 1).

O paciente apresentava arco superior atrésico e em forma de $V$, apinhamentos dentários, ausências dentárias e elementos dentários em erupção. Foram realizadas exodontias de dentes decíduos devido à retenção prolongada destes e avaliação da rizogênese dos permanentes sucessores, através do exame radiográfico. Foi instalada uma Placa Lábio Ativa inferior, com intuito de eliminar a intensa ação dos músculos orbital e mentoal sob os dentes anteroinferiores, possibilitando sua correta inclinação e desenvolvimento ósseo junto à sínfise (Figura 2). A avaliação radiográfica revelou que os elementos 11 e 21 estavam impactados, o elemento 28 em erupção desfavorável e foi possível observar 3 elementos supranumerários (mesiodentes) (Figura 3).

Aos 12 anos, o paciente encontrava-se em tratamento ortodôntico para correção dos apinhamentos. Ao exame clínico, foi possível observar dentição mista, com elementos permanentes ainda ausentes. Os elementos 43 e 33 encontravam-se em infraoclusão. Ao exame radiográfico, pôde-

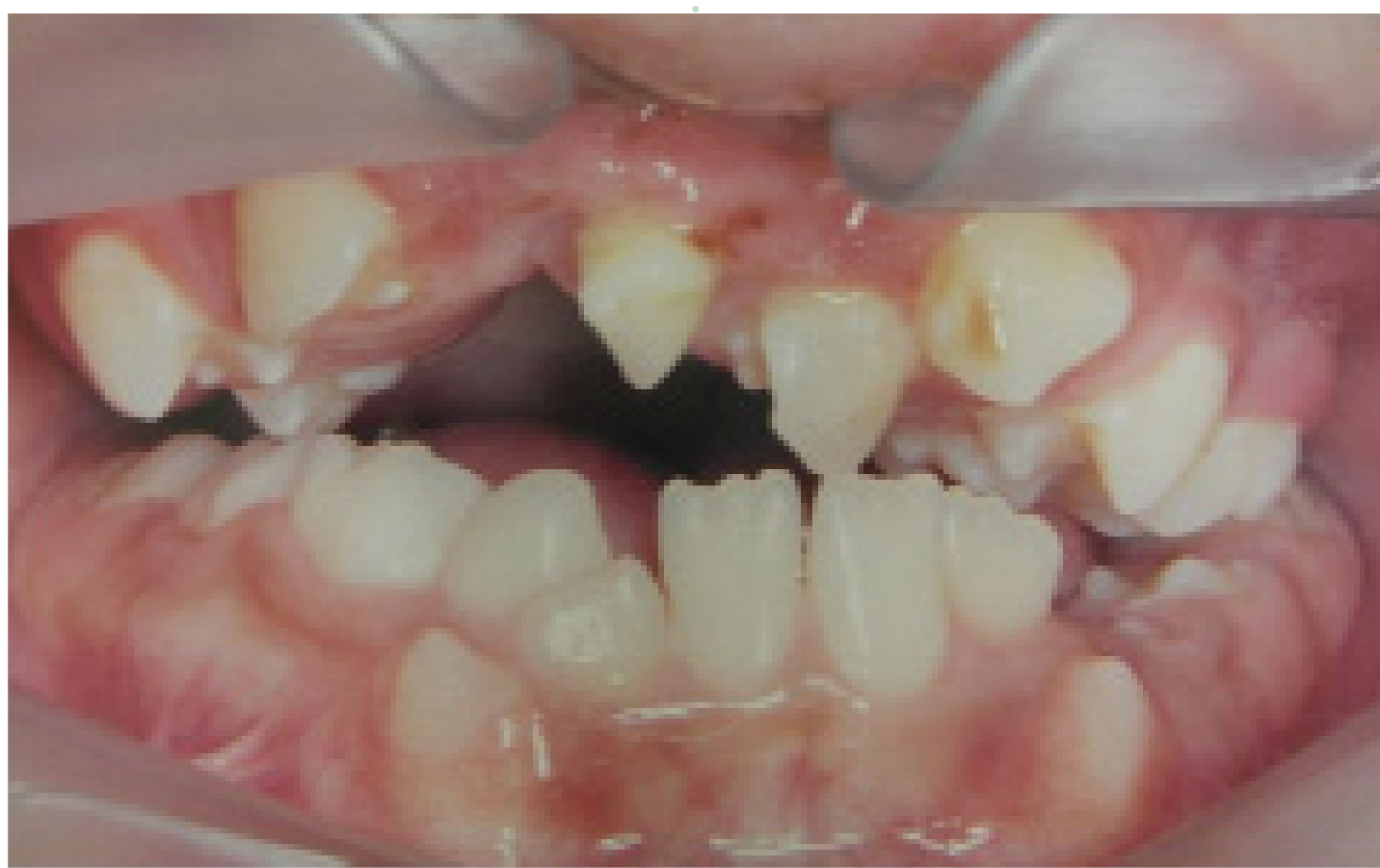

Figura 3: Arco superior atrésico e em forma de $V$, apinhamentos dentários, ausências dentárias e elementos dentários em erupção.
GOMES LD

SILVA AMP

TANNURE PN

MANIFESTAÇÕES

BUCAIS DA

SÍNDROME DE

APERT: RELATO DE

cASO CLÍNICO

$\therefore 279$.

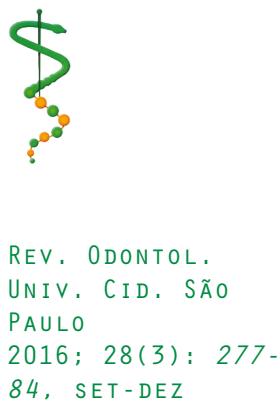


GOMES LD

SILVA AMP

TANNURE PN

MANIFESTAÇÕES

BUCAIS DA

SINNDROME DE

APERT: RELATO DE

CASO CLÍNICO

REV, ODONTOL

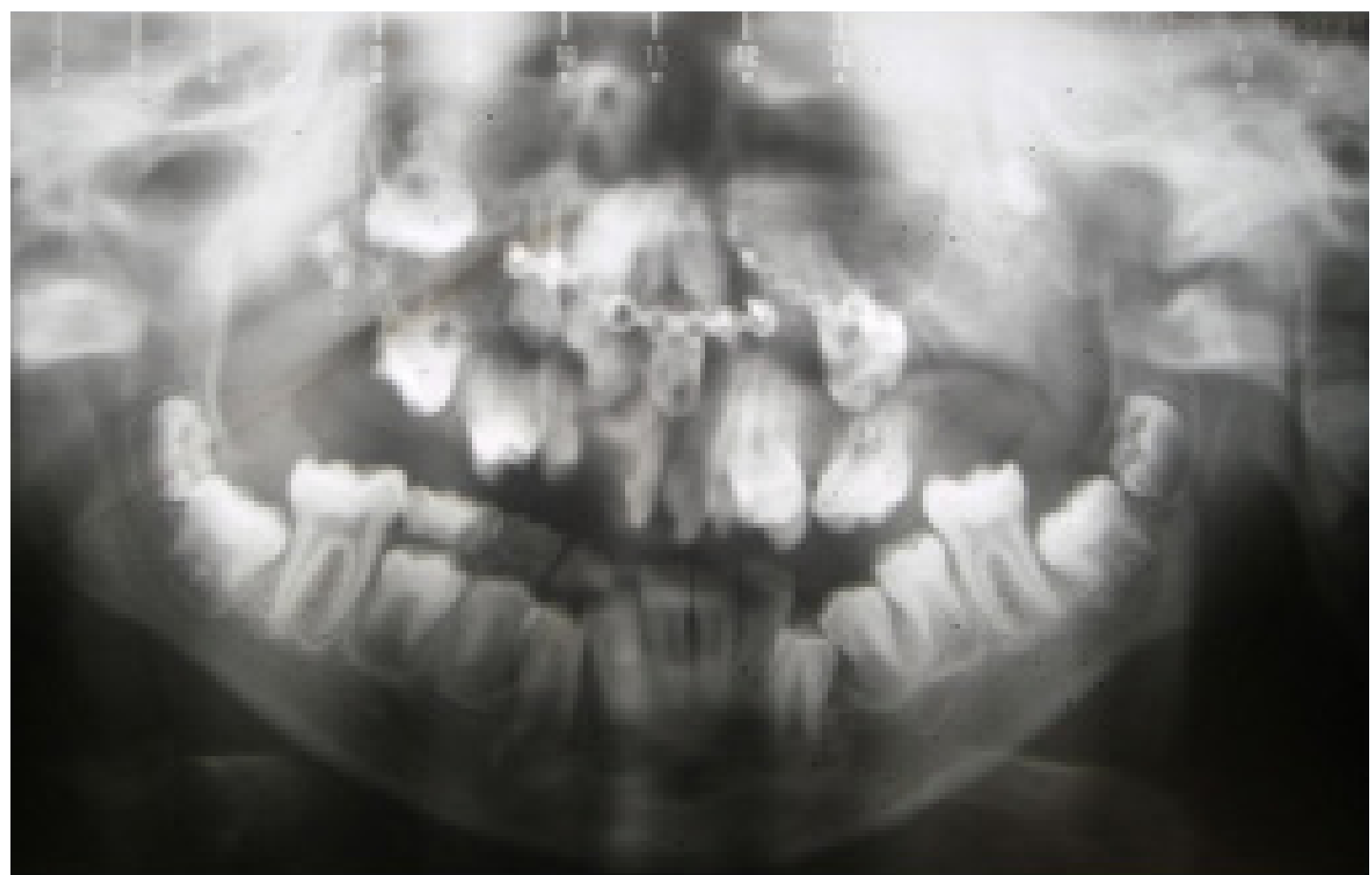

Figura 4: Radiografia panorâmica evidenciou que os elementos 18, 16, 38 e 48 estavam em formação, os elementos 11 e 21 impactados, o elemento 28 encontrava- se em erupção desfavorável e na região de incisivos centrais superiores foi possivel observar 3 elementos supranumerários (mesiodentes).

-se observar a presença de placa cirúrgica para osteossíntese na região nasal e na região de assoalho de órbita esquerda, evidenciando que o paciente foi submetido a cirurgia de alongamento de terço médio da face, muito comum em portadores de craniossinostose sindrômica. Foi realizada pelo método de distração osteogênica, utilizando-se aparelho extremo rígido (RED - rigid extremal device). Pôde-se destacar que os dentes 16, 21 e 26 apresentavam anomalia de forma. Foi evidenciada, também, a presença de imagem radiopaca na região posterior esquerda e direita da maxila que sugeria um dente ectópico (Figura 4 e Figura 5).

Aos 13 anos, o paciente encontrava-se com uma má oclusão classe III. Houve uma diminuição da discrepância anteroposterior entre o terço médio e o inferior da face. Foi observado que todos os dentes estavam hígidos, com ausência de apinhamento devido ao tratamento ortodôntico, além de uma maior proporcionalidade entre o tamanho dos dentes e a forma dos arcos. Ao exame radiográfico, o elemento 17 estava incluso e situado na interseção maxila-malar-seio maxilar. Os elementos 14 e 27 estavam impactados,
37 e 47 inclusos. Além disso, ainda havia a presença de 2 ou mais dentes ectópicos inclusos, localizados na região do 12, 11 e 21 e microdontia do 18 e 28.

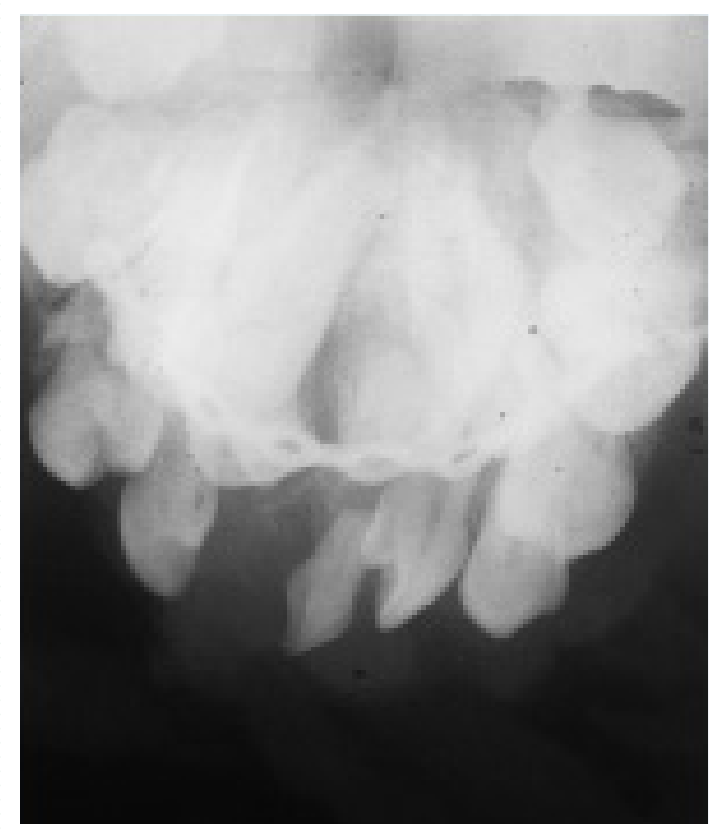

Figura 5: Radiografia oclusal com os elementos 11 e 21 impactados e na região de incisivos centrais superiores foi possível observar 3 elementos supranumerários (mesiodentes). 


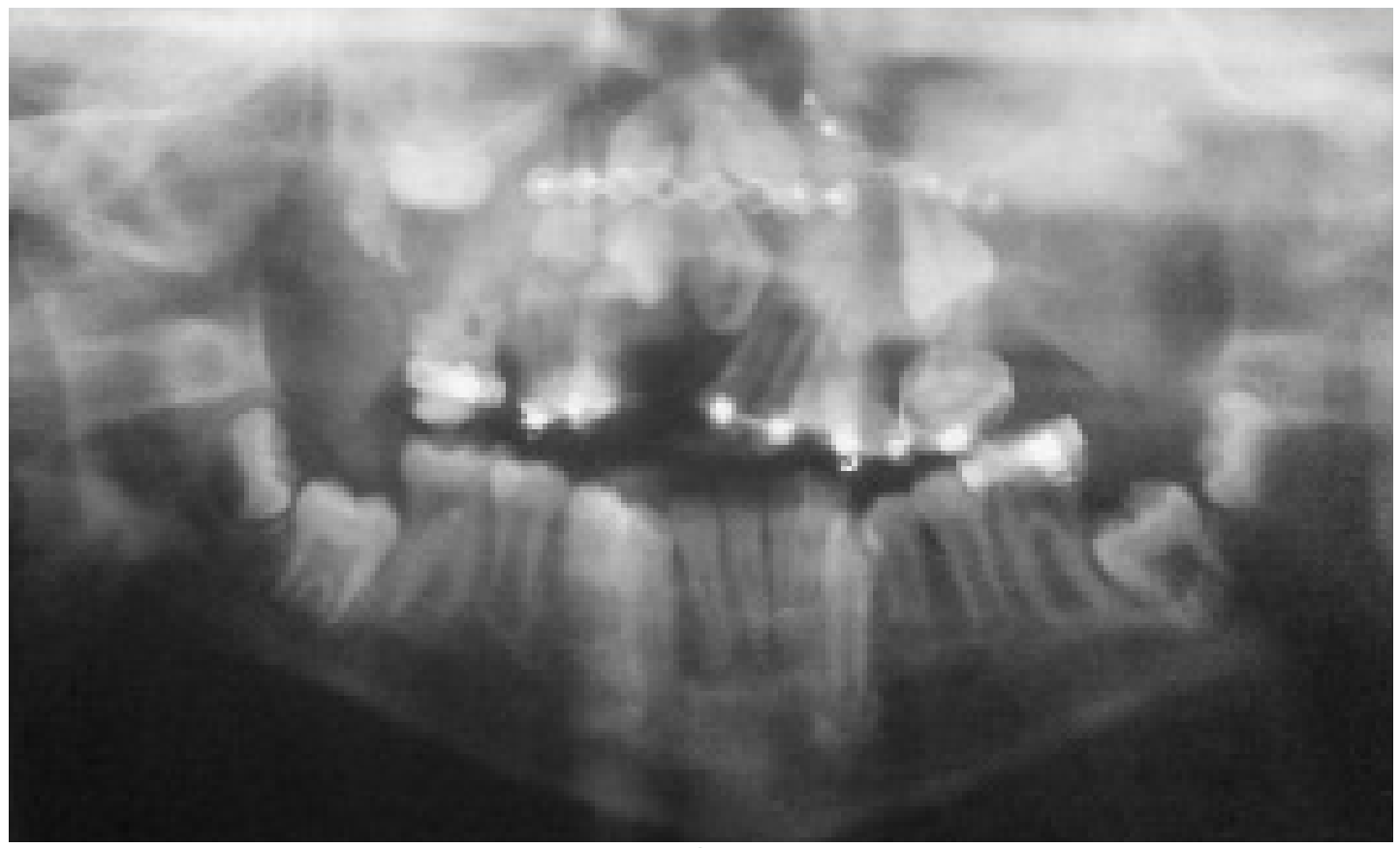

GOMES LD

SILVA AMP

TANNURE PN

MANIFESTAÇÕES

BUCAIS DA

SÍNDROME DE

APERT: RELATO DE

CASO CLÍNICO

Figura 6: Observa-se em radiografia panorâmica a presença de placa cirúrgica para osteossíntese na região nasal e na região de assoalho de órbita esquerda. Alguns elementos dentários inclusos foram observados, são eles: $2^{\circ}$ molar, $2^{\circ}$ pré-molar, canino, incisivo central superior direito, incisivo central, canino, $2^{\circ}$ molar superior esquerdo, $2^{\circ}$ e $3^{\circ}$ molares inferior esquerdo e direito, os dentes 16, 21 e 26 apresentavam anomalia de forma imagem radiopaca na região posterior esquerda e direita da maxila que sugeria um dente ectópico.
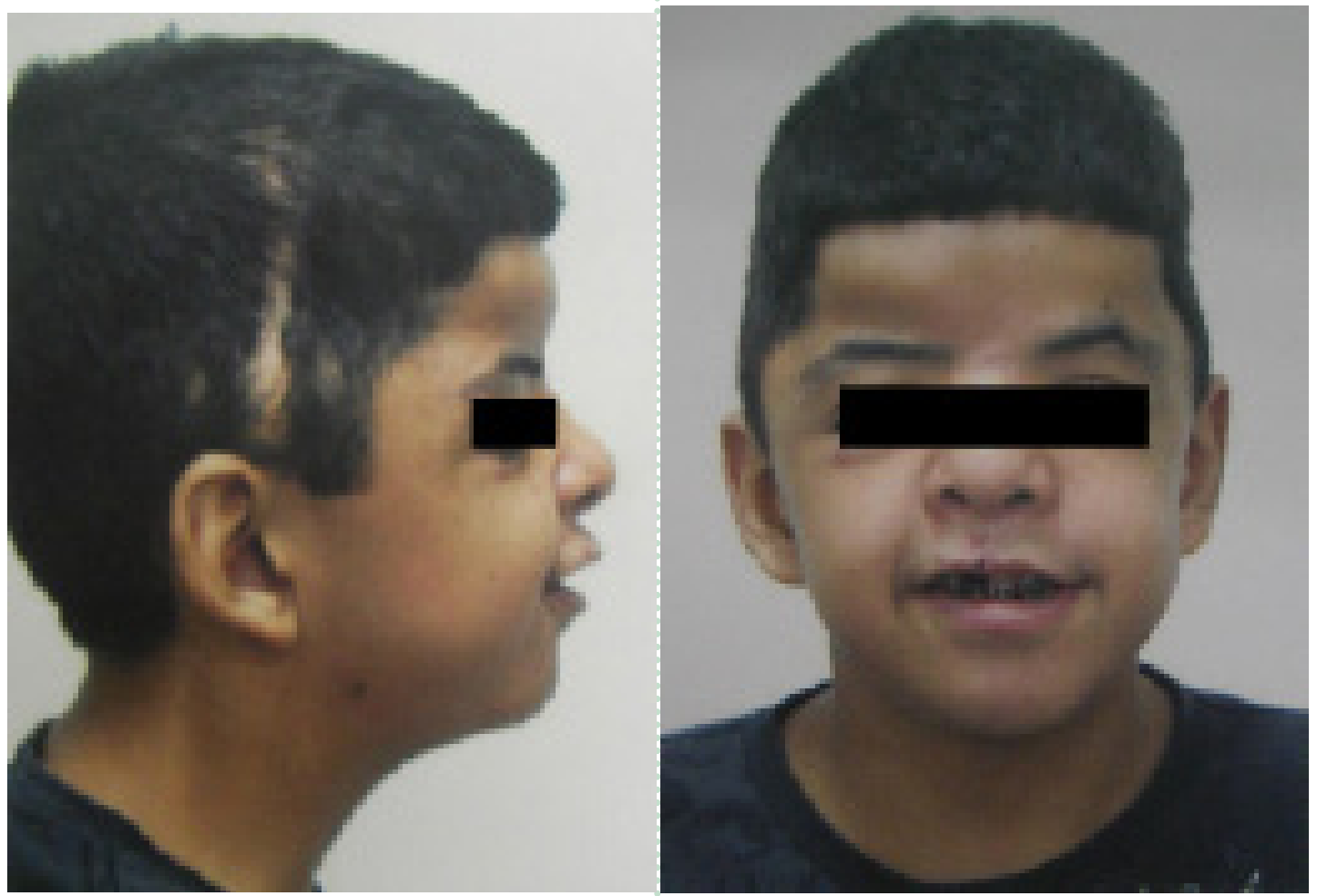

Figura 7: Má oclusão Classe III, diminuição da discrepância anteroposterior entre o terço médio e inferior da face. 
GOMES LD

SILVA AMP

TANNURE PN

MANIFESTAÇÕES

BUCAIS DA

SINNDROME DE

APERT: RELATO DE CASO CLÍNICO

$282 \ldots$

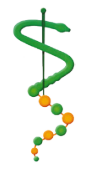

REV, ODONTOL.

UNIV, CID, SÃO

PAULO

$2016 ; 28(3): 277$

84, SET-DEZ

\section{I SCUSSÃ0}

A Síndrome de Apert, também chamada de acrocefalossindactilia tipo 1, é caracterizada pelo encerramento prematuro das suturas cranianas (craniossinostose), sindactilia simétrica das mãos e dos pés e anomalias faciais da linha média ${ }^{4}$. A síndrome de Apert autossômica de herança dominante é atribuída a mutações nos receptores do fator de crescimento de fibroblastos (FGFR-2) ${ }^{4}$.

A cavidade bucal de pacientes com Apert é bastante característica. Observa-se uma redução no tamanho da maxila, em particular na direção anteroposterior. Essa redução pode resultar em apinhamento dentário e numa mordida aberta anterior da maxila. A mandíbula normalmente está dentro do tamanho e da forma normal e simula um pseudoprognatismo. Anomalias dentárias, tais como dentes inclusos, erupção retardada, dentes supranumerários e gengiva espessa também são comuns ${ }^{5,6,7,8}$. A hipoplasia da maxila produz uma forma em $\mathrm{V}$ do arco superior e apinhamento dentário. Tipicamente, a má oclusão tipo classe III ocorre e pode estar associada à mordida aberta anterior e cruzada posterior. São observadas tumefações ao longo da parte lateral do palato duro devido ao acúmulo de glicosaminoglicanos, especialmente o ácido hialurônico. Essas tumefações costumam aumentar com a idade, produzindo uma pseudofenda do palato duro. O espessamento da gengiva pode estar associado à erupção retardada dos dentes. Além disso, incisivos em forma de pá têm sido descritos em um terço dos pacientes ${ }^{2}$. No caso relatado, provavelmente, o aumento de volume encontrado na maxila seria proveniente do acúmulo de glicosaminoglicanos, sem alteração de volume em osso. Essa característica pode ser visualizada através das imagens radiográficas panorâmicas realizadas pelo paciente.

O paciente B.S.D., ainda na infância, foi submetido a duas cirurgias de avanço de terço médio da face com auxílio de aparelho de RED para correção da má oclusão do tipo Classe III. Isso proporcionou uma oclusão semelhante à má oclusão do tipo Classe II. Essa oclusão foi obtida propositalmente, pois, durante o desenvolvimento a mandíbula tomou sua posição anteriorizada novamente como forma de compensação, como visto durante o acompanhamento clínico.

Durante a adolescência, o paciente encontrava-se com perfil reto e oclusão topo a topo. O tratamento ortodôntico favoreceu a erupção de alguns dentes permanentes e foi necessário para preparar o paciente para a cirurgia ortognática. A manutenção ortodôntica pós-cirúrgica é um componente importante da correção oclusal definitiva após procedimentos como a cirurgia ortognática ${ }^{9}$. Vale ressaltar que o paciente ainda encontra-se em tratamento ortodôntico, porém já são notórios grandes avanços no que diz respeito à função e estética.

Na puberdade, realiza-se o avanço do terço médio facial para melhorar o fluxo aéreo-nasal. A cirurgia ortognática é a fase final para ajustar a mordida e aperfeiçoar

a estética, sendo planejada para a adolescência ${ }^{10}$. Apesar de realizada a cirurgia, o paciente ainda apresentava respiração bucal noturna, entretanto, com relação à estética, pôde-se observar nítida melhora.

No caso relatado, não foi observada hipoplasia de esmalte nos elementos dentários. Em contrapartida, o paciente possuía elementos com alterações de número e forma, além de problemas de erupção por impacção dentária. A atenção também deve estar voltada para a higiene oral do paciente, visto que a maioria dessas alterações contribui para o acúmulo de placa. O paciente recebia a supervisão do responsável durante a escovação e nunca apresentou lesões cariosas.

Diferentes graus de deficiência mental têm sido associados com a síndrome de Apert. Os indivíduos que fizeram craniectomia no início da vida podem ter melhorado a inteligência ${ }^{11}$. No caso relatado, ainda na infância, o paciente foi submetido a tais cirurgias junto à realização de cirurgias de face. De acordo com exames e avaliações, foram percebidas alterações de audição, rebaixamento da eficiência intelectual $(2 \%)$, além de dificuldade de respiração, deglutição e fonética. Por esse motivo foram envolvidas a fonoaudiologia, a psicopedagogia e a terapia ocupa- 
cional no tratamento.

A marcha do paciente descrito também foi prejudicada junto à eficiência em segurar objetos, visto que a sindactilia é um fator patognomônico dessa síndrome. O paciente foi submetido a cirurgia para correção dos pés e mãos, acompanhada da fisioterapia. Essa dificuldade de caminhar e a firmeza nas mãos não estão relacionadas a distúrbios motores ou reflexos, mas simplesmente ao fator anatômico. A sindactilia em pé pode envolver principalmente três dígitos (tipo I) ou dígitos de duas de cinco anos com um dedo do pé separado (tipo II) ou ser contínua (tipo III) ${ }^{11}$.

Considerando uma grande probabilidade de apresentar alterações na cavidade bucal, os pacientes com síndrome de Apert provavelmente necessitarão de tratamento odontológico. Assim, os cirurgi-
Ões-dentistas devem estar bem informados sobre as características da cavidade bucal desses indivíduos. O conhecimento sobre estes transtornos é fundamental para estabelecer um plano de tratamento adequado às suas necessidades ${ }^{10,12,13}$.

\section{CONCLUSÃO}

Os pacientes portadores da Síndrome de Apert devem receber acompanhamento multidisciplinar e o cirurgião-dentista deve fazer parte dessa equipe. Neste caso, o tratamento ortodôntico favoreceu a estética, a função e a fonética do paciente, proporcionando a ele uma melhor qualidade de vida.

\section{AGRADEC IMENTOS}

À Dra. Lídia Protzenko Cervante pelo tratamento executado.
GOMES LD

SILVA AMP

TANNURE PN

MANIFESTAÇÕES

BUCAIS DA

SÍNDROME DE

APERT: RELATO DE

CASO CLINICO

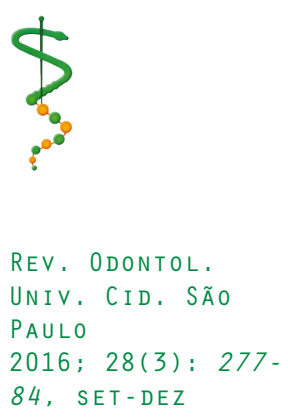


GOMES LD

SILVA AMP

TANNURE PN

MANIFESTAÇÕES

BUCAIS DA

SINNDROME DE

APERT: RELATO DE

CASO CLÍNICO
1 - Letra A, de Almeida AL, Kaizer R, Esper LA, Sgarbosa S, Granjeiro JM. Intraoral features of Apert's syndrome. Oral surgery, oral medicine, oral pathology, oral radiology, and endodontics. 2007;103(5): e38-41.

2- Castro-Silva I, Nascimento L, Coutinho L, Costa D. Criança com Síndrome de Apert: diagnóstico clínico-radiográfico, manifestações orofaciais e qualidade de vida. Rev Odontol Bras Central. 2014;23(66).

3- Longhi I, Silva S. Síndrome de Apert. Rev Fac Odontol Passo Fundo. 2002;7(1):55-60.

4- Jong T, Maliepaard M, Bannink N, Raat H, Mathijssen IM. Health-related problems and quality of life in patients with syndromic and complex craniosynostosis. Child's nervous system : ChNS : official journal of the International Society for Pediatric Neurosurgery. 2012;28(6):879-82.

5- Varoli F, Santos K, Costa C, Oliveira J. Apert syndrome: clinical and radiographic features and case report. Rev Odonto Cienc. 2011;26(1):96-9.

6- Albuquerque M, Cavalcanti M. Computed tomography assessment of Apert syndrome. Brazilian Oral Research. 2004;18(1):35-9.

7- Verma S, Draznin M. Apert syndrome. Dermatology online journal. 2005; 11(1):15.
8- Surman TL, Logan RM, Townsend GC, Anderson PJ. Oral features in Apert syndrome: a histological investigation. Orthodontics \& craniofacial research. 2010;13(1):61-7.

9- Nurko C, Quinones R. Dental and orthodontic management of patients with Apert and Crouzon syndromes. Oral and maxillofacial surgery clinics of North America. 2004;16(4):541-53.

10-Hohoff A, Joos U, Meyer U, Ehmer U, Stamm T. The spectrum of Apert syndrome: phenotype, particularities in orthodontic treatment, and characteristics of orthognathic surgery. Head \& face medicine. 2007;3:10.

11 - Kannan VP. Apert syndrome. Journal of the Indian Society of Pedodontics and Preventive Dentistry. 2010;28(4):3225.

12 - Dalben G S, das Neves LT, Gomide MR. Oral findings in patients with Apert syndrome. Journal of applied oral science : revista FOB. 2006;14(6):4659.

13- Ileri Z, Goyenc YB. Apert syndrome: A case report. European journal of dentistry. 2012;6(1):110-3.

Recebido em 06/09/2016

Aceito em 01/12/2016 